\title{
Evaluation of corrosion on the fuel performance of stainless steel cladding
}

\author{
Daniel de Souza Gomes ${ }^{1}$, Alfredo Abe ${ }^{1}$, Antonio Teixeira e Silva ${ }^{1}$, Claudia Giovedi ${ }^{2}{ }^{*}$, and Marcelo Ramos Martins ${ }^{2}$ \\ ${ }^{1}$ Nuclear and Energy Research Institute - IPEN/CNEN, Nuclear Engineering Center - CEN, Av. Prof. Lineu Prestes 2242, \\ São Paulo, SP, Brazil \\ ${ }^{2}$ LabRisco, University of São Paulo, Av. Prof. Mello Moraes 2231, São Paulo, SP, Brazil
}

Received: 13 October 2015 / Received in final form: 18 February 2016 / Accepted: 7 September 2016

\begin{abstract}
In nuclear reactors, the use of stainless steel (SS) as the cladding material offers some advantages such as good mechanical and corrosion resistance. However, its main advantage is the reduction in the amount of the hydrogen released during loss-of-coolant accident, as observed in the Fukushima Daiichi accident. Hence, research aimed at developing accident tolerant fuels should consider SS as an important alternative to existing materials. However, the available computational tools used to analyze fuel rod performance under irradiation are not capable of assessing the effectiveness of SS as the cladding material. This paper addresses the SS corrosion behavior in a modified fuel performance code in order to evaluate its effect on the global fuel performance. Then, data from the literature concerning to SS corrosion are implemented in the specific code subroutines, and the results obtained are compared to those for Zircaloy-4 (Zy-4) under the same power history. The results show that the effects of corrosion on SS are considerably different from those on Zy-4. The thickness of the oxide layer formed on the SS surface is considerably lower than that formed on Zy-4. As a consequence of this, the global fuel performance of SS under irradiation should be less affected by the corrosion.
\end{abstract}

\section{Introduction}

In early pressurized water reactors (PWRs), iron-based alloys were chosen as the materials for manufacturing fuel rod claddings. Nonetheless, since 1960, these materials have been replaced with zirconium-based alloys (Zy) in commercial reactor cores mainly because of the latter's lower absorption cross section for thermal neutrons, which make them more cost effective. However, under design-basis and beyonddesign-basis scenarios, Zy present an accelerated oxidation reaction with an important hydrogen release, which compromises the safe operation of light water reactors [1].

One of the advantages of using stainless steel (SS) as the cladding is that it has better corrosion resistance than $\mathrm{Zy}$. Extensive information has been acquired over a long period about the performance of SS as the material for structural reactor components under normal operating conditions; this information has confirmed the higher corrosion resistance of SS. Particularly at high temperatures, the magnitude of the parabolic oxidation rate constants for SS are approximately two to three orders of magnitude lower than that for $\mathrm{Zy}[2]$.
In general, SS suffers from intergranular attacks, which result in the loss of plasticity and strength because of crystal structure deformation caused by a localized attack along the grain. In these alloys, the resistance to intergranular stress corrosion cracking (IGSCC) is improved by reducing the carbon content (maximum of $0.03 \%$ ), as in the case of steel types $304 \mathrm{~L}$ and $316 \mathrm{~L}$. Stabilization is achieved in the 300 series austenitic steel grades by adding some chemical elements such as titanium, niobium, and tantalum. These balanced additions may prevent the IGSCC precipitation of metallic carbide $\left(\mathrm{M}_{23} \mathrm{C}_{6}\right)$ in the region of the grain boundaries and avoid the depletion of chromium [3].

The SS types used as the cladding material in the first PWR were the austenitic SS types 304, 347, and 348 . Except for small isolated failures, the performance of these SS types is considered excellent [4].

The assessment of fuel rod performance when using SS as the cladding material requires a previous step of modifying regular fuel performance codes in order to introduce the properties and correlations of this material. Accordingly, the code FRAPCON-3.4 was used as the basis to construct the code IPEN-CNEN/SS, which was used to evaluate the fuel rod performance when using 348 SS as the cladding material [5].

The first version of IPEN-CNEN/SS did not take into account cladding corrosion under irradiation. Then, an updated version was constructed by changing the subrou-

\footnotetext{
* e-mail: claudia.giovedi@labrisco.usp.br
} 
Table 1. Properties of different oxides at room temperature $[10,15]$.

\begin{tabular}{lllll}
\hline Oxide & $\begin{array}{l}\text { Density } \\
\left(\mathrm{kg} / \mathrm{m}^{3}\right)\end{array}$ & $\begin{array}{l}\text { Thermal conductivity } \\
\left(\mathrm{W} / \mathrm{m}^{\circ} \mathrm{C}\right)\end{array}$ & $\begin{array}{l}\text { Melting point } \\
\left({ }^{\circ} \mathrm{C}\right)\end{array}$ & $\begin{array}{l}\text { Crystal } \\
\text { structure }\end{array}$ \\
\hline $\mathrm{FeO}$ & 5745 & 3.0 & 1377 & Cubic \\
$\mathrm{Fe}_{2} \mathrm{O}_{3}$ & 5250 & 3.3 & 1565 & Cubic \\
$\mathrm{Fe}_{3} \mathrm{O}_{4}$ & 5170 & 3.9 & 1597 & Hexagonal \\
$\mathrm{ZrO}_{2}$ & 5380 & 1.7 & $2681-2847$ & Monoclinic \\
$\mathrm{Cr}_{2} \mathrm{O}_{3}$ & 5210 & $9.99-32.94$ & 2380 & Hexagonal \\
\hline
\end{tabular}

tine related to the waterside corrosion cladding in the fuel performance code. The correlations associated to the SS waterside corrosion were obtained by searching the open literature related to $304 \mathrm{SS}$, with the aim of achieving a conservative assumption [6].

The aim of this paper is to evaluate the steady-state fuel rod corrosion when using SS as the cladding material and to compare SS with Zircaloy-4 (Zy-4) under the same power history.

\subsection{Cladding corrosion}

Over the last few decades, many studies have been conducted on the chemical process of corrosion of alloys used in nuclear applications. For PWRs, an important research topic is the study of the quantity of oxide buildup on the waterside [7], specifically in cladding materials. The oxidization process can be described as a function of the cladding temperature, which is approximately $320-350{ }^{\circ} \mathrm{C}$, and the fast neutron flux, which ranges from 6 to $9 \times 10^{17} \mathrm{n} / \mathrm{m}^{2} \mathrm{~s}$. Furthermore, this process presents chemical correlations with the boric acid concentration in the coolant [8]. The process is very complex because of the severe conditions found in the core of nuclear power plants.

A synthesis and a comparison of the observed corrosion behavior under steady state irradiation for the studied cladding materials are presented in the following sections.

\subsubsection{Corrosion of stainless steel (SS)}

The chromium content plays an important role to define the composition of the oxide layer formed on the SS cladding [9].

In SS containing low chromium, the oxidation process is based on the buildup iron oxide film. The oxidation mechanism produces a sequence of layers, starting with a layer with the lowest oxygen content $(\mathrm{FeO})$, followed by an intermediate layer $\left(\mathrm{Fe}_{3} \mathrm{O}_{4}\right)$, and finally, a thin more dominant oxygen-rich layer $\left(\mathrm{Fe}_{2} \mathrm{O}_{3}\right)$; this mechanism is also found in the oxidation of pure iron. In SS containing high chromium, it is observed that the first layer is formed by chromium oxide $\left(\mathrm{Cr}_{2} \mathrm{O}_{3}\right)$ [10], which has higher thermal conductivity than iron oxides [11]. Then, the excellent corrosion and oxidation resistances of SS from 300 series can be attributed to the initial layer of $\mathrm{Cr}_{2} \mathrm{O}_{3}$ (approximately $1-3 \mathrm{~nm}$ thick), which is formed at the cladding surface and prevents further surface corrosion. In addition, the varying amount of chromium in SS produces variations in the corrosion kinetics [12].

\subsubsection{Corrosion of zirconium-based alloys (Zy)}

The oxidation behavior of zirconium-based alloys (Zy) by water in a PWR during normal operation is an electrochemically driven process that occurs in two phases, accompanied by hydrogen absorption. Initially, a thin protective black oxide film containing mostly tetragonal zirconium oxide (an allotropic form that is stable at high pressure and temperature), $\mathrm{ZrO}_{2}$, is formed [13]. Later, the tetragonal phase becomes unstable, and the oxide changes to a monoclinic form. At this stage, the corrosion layer shows some porosity, consequently, only a portion of the oxide layer remains protective, and the corrosion is controlled by diffusion through the dense protective layer only [14].

\subsubsection{Comparison of different oxides behavior}

Zirconia $\left(\mathrm{ZrO}_{2}\right)$ undergoes a transition from the stable phase at room temperature, changing from a monoclinic to a tetragonal crystal structure at high pressure and temperature [15]. On the other hand, iron oxides do not undergo such transformation [16].

It has been observed that at temperatures below $500^{\circ} \mathrm{C}$, thin oxide films on SS cause very large changes in emittance, which varies by a factor of around 5 (0.15 to 0.85$)$ [16].

Table 1 summarizes some properties of different oxides at room temperature.

The thermal conductivity of the oxides formed in SS differs from that of the oxides formed in Zy [6], as shown in Figure 1. The steel oxides conductivity decreases with increasing temperature differently from the behavior of $\mathrm{Zy}$.

\section{Methodology}

\subsection{IPEN-CNEN/SS2 code}

The basis for new fuel codes was the FRAPCON-3.4 code [17], which is sponsored by the United States Nuclear Regulatory Commission, for the licensing of PWR and boiling water reactors (BWR) nuclear power plants.

In the first version of the modified code, IPEN-CNEN/ SS, a new set of correlations was implemented for 348 SS in relation to thermal expansion, heat conductivity, elasticity modulus, Poisson's ratio, irradiation creep, and swelling to check the performance of a SS fuel rod [5]. The second version, named IPEN-CNEN/SS2, was 
- - - Zirconia $\quad$.......... Steel oxides

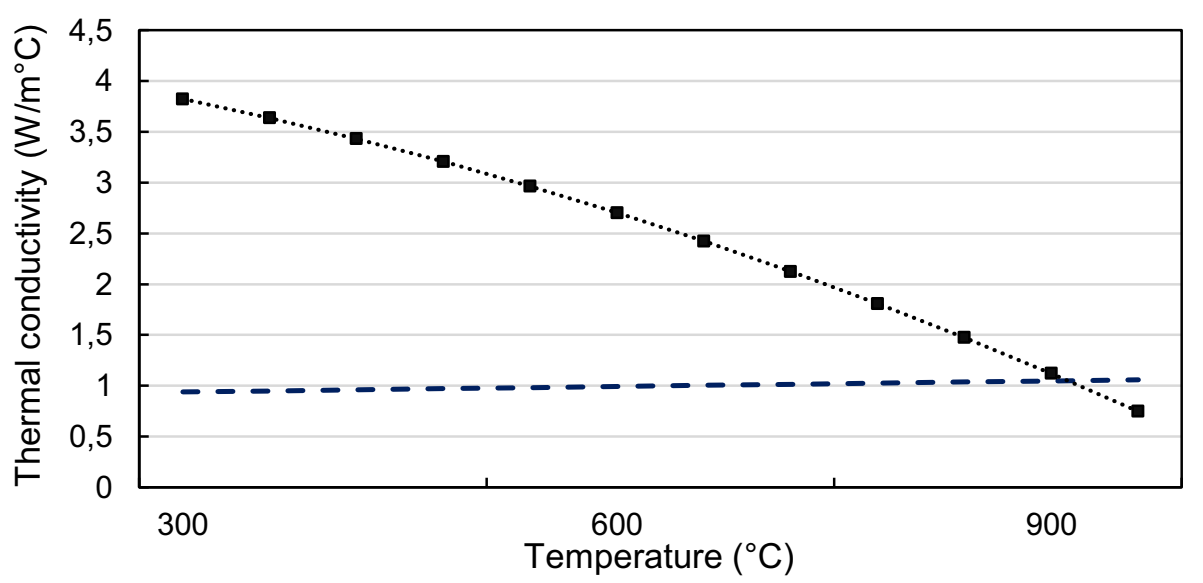

Fig. 1. Thermal conductivity data from literature [6] as a function of temperature of steel oxides and zirconia.

Table 2. Reactor thermal hydraulics parameters.

\begin{tabular}{ll}
\hline Parameter & Value \\
\hline Rated core heat & $2815 \mathrm{MWt}$ \\
Heat generated in fuel & $97.4 \%$ \\
Coolant system pressure & $15.5 \mathrm{MPa}$ \\
Coolant in let temperature & $289.7^{\circ} \mathrm{C}$ \\
Linear average power of fuel rod & $17.75 \mathrm{~kW} / \mathrm{m}$ \\
Coolant mass flux & $5900 \mathrm{~kg} / \mathrm{s} \mathrm{m}^{2}$ \\
Average coolant velocity along rods & $4.97 \mathrm{~m} / \mathrm{s}$ \\
\hline
\end{tabular}

developed by modifying the IPEN-CNEN/SS subroutine related to the cladding waterside corrosion at low temperature. This new version provided an expression for the thickness of the oxide layer on the waterside surface during typical reactor operation at temperatures from 250 to $400{ }^{\circ} \mathrm{C}$. The input parameters for this version were the outer surface temperature, initial oxide film thickness, and time interval [16]. Irradiation effect was not taken into account for the SS in the modified version of the fuel performance code.

The adapted code focused on the material property libraries related to 304 SS [6]. The modified subroutine included the parameters thermal conductivity and weight gain. The properties included in the code were the melting point, specific heat capacity, enthalpy, thermal conductivity, dimensional expansion, and density. The subroutine related to oxide emissivity was changed in the first version of the modified code (IPEN-CNEN/SS) by considering the value obtained from the literature for $348 \mathrm{SS}$.

\subsection{PWR general data}

The steady-state irradiation performance of a 348 SS fuel rod was simulated using IPEN-CNEN/SS2. The results were compared with those obtained for a $\mathrm{Zy}-4$ fuel rod calculated using FRAPCON-3.4 under the same power
Table 3. Fuel rod data for fuel performance code startup for Zy-4 and SS claddings.

\begin{tabular}{ll}
\hline Parameter & Value \\
\hline Irradiation time & $40080 \mathrm{~h}$ \\
Cladding outer diameter & $9.7 \mathrm{~mm}$ \\
Cladding inner diameter & $8.43 \mathrm{~mm}$ \\
Cladding wall thickness & $0.635 \mathrm{~mm}$ \\
Cladding roughness & $0.000508 \mathrm{~mm}$ \\
Cladding material & $\mathrm{Zy}-4 / 348 \mathrm{SS}$ \\
Fuel pellet diameter & $8.25 \mathrm{~mm}$ \\
Fuel stack height & $3.81 \mathrm{~m}$ \\
Fuel pellet density & $10.41 \mathrm{~g} / \mathrm{cm}^{3}$ \\
Fuel pellet roughness & $0.000762 \mathrm{~mm}$ \\
Fuel pellet sintering temperature & $1600{ }^{\circ} \mathrm{C}$ \\
Fuel pellet resintering density change & $150 \mathrm{~kg} / \mathrm{m}^{3}$ \\
U-235 enrichment & $3.48 \%$ \\
Plenum length & $27.17 \mathrm{~cm}$ \\
Rod internal (He) pressure & $2.62 \mathrm{MPa}$ \\
Fuel rod pitch & $1.27 \mathrm{~cm}$ \\
\hline
\end{tabular}

history. The primary objective was to verify the differences in cladding corrosion because the general behavior under irradiation was previously studied [5].

The data used to prepare the input data were those of a conventional PWR fuel rod that employed Zy-4 as the cladding material. The same design was used in the simulations using FRAPCON-3.4 and IPEN-CNEN/SS2 to facilitate comparison of the obtained results. However, it is important to take into account that small changes in the design parameters such as the cladding thickness and rod pitch should be implemented to optimize the performance of the SS fuel rod. Table 2 lists the reactor conditions and thermal hydraulics parameters, and Table 3 lists the fuel rod data for the startup file used to perform the simulations. 


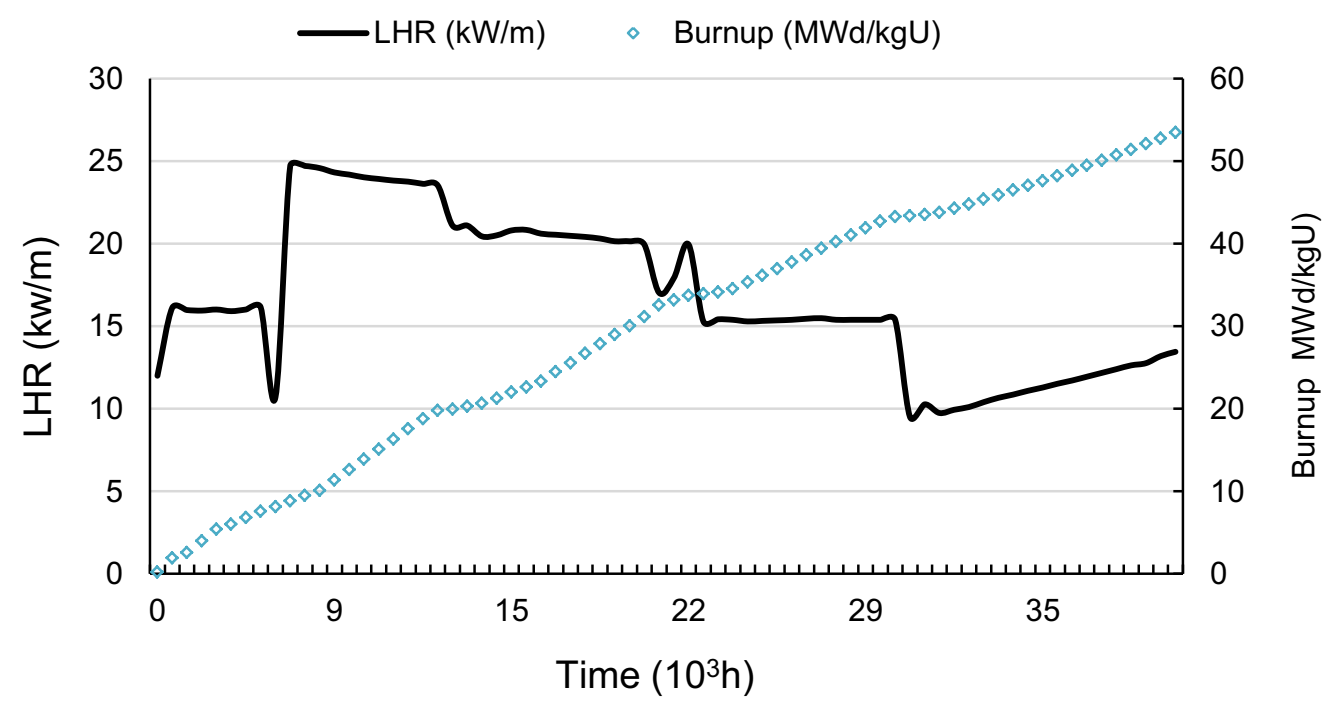

Fig. 2. Variations in fuel rod average linear heat rating $(\mathrm{kW} / \mathrm{m})$ and burnup $(\mathrm{MW} \mathrm{d} / \mathrm{kg} \mathrm{U})$ as a function of irradiation time.

Table 4. Data obtained from simulation for Zy-4 fuel rod using FRAPCON-3.4.

\begin{tabular}{lrlllll}
\hline & Time $(\mathrm{h})$ & $\begin{array}{l}\text { Burnup } \\
(\mathrm{MW} \mathrm{d} / \mathrm{kg} \mathrm{U})\end{array}$ & $\begin{array}{l}\text { Power } \\
(\mathrm{kW} / \mathrm{m})\end{array}$ & $\begin{array}{l}\text { Average cladding } \\
\text { temperature }\left({ }^{\circ} \mathrm{C}\right)\end{array}$ & $\begin{array}{l}\text { Fuel centerline } \\
\text { temperature }\left({ }^{\circ} \mathrm{C}\right)\end{array}$ & $\begin{array}{l}\text { Oxide layer } \\
\text { thickness }(\boldsymbol{\mu})\end{array}$ \\
\hline $\mathbf{1}$ & 235 & 0.24 & 12.17 & 311 & 526 & 0.5 \\
$\mathbf{2}$ & 5035 & 6.80 & 15.91 & 318 & 579 & 1.3 \\
$\mathbf{3}$ & 7373 & 9.94 & 24.70 & 333 & 708 & 1.5 \\
$\mathbf{4}$ & 9353 & 14.05 & 24.18 & 333 & 683 & 2.8 \\
$\mathbf{5}$ & 12629 & 20.71 & 23.62 & 332 & 642 & 3.0 \\
$\mathbf{6}$ & 14069 & 26.38 & 10.66 & 327 & 596 & 4.6 \\
$\mathbf{7}$ & 16711 & 28.02 & 20.47 & 327 & 608 & 6.9 \\
$\mathbf{8}$ & 20237 & 34.06 & 19.95 & 327 & 613 & 21.1 \\
$\mathbf{9}$ & 22404 & 33.39 & 15.42 & 335 & 552 & 27.9 \\
$\mathbf{1 0}$ & 25368 & 37.27 & 15.39 & 336 & 558 & 26.4 \\
$\mathbf{1 1}$ & 28704 & 41.66 & 15.39 & 336 & 566 & 28.7 \\
$\mathbf{1 2}$ & 30480 & 45.94 & 9.74 & 318 & 463 & 30.7 \\
$\mathbf{1 3}$ & 34320 & 49.39 & 11.09 & 323 & 493 & 32.8 \\
$\mathbf{1 4}$ & 37512 & 52.58 & 12.17 & 326 & 517 & 541 \\
$\mathbf{1 5}$ & 40080 & 55.37 & 13.19 & 329 & & \\
\hline
\end{tabular}

A cosine axial power distribution was applied in the simulations. The fuel rod average linear heat rating used in the simulation and the achieved burnup for the hottest node are shown in Figure 2.

\section{Results and discussion}

The simulations were performed by applying the same power history under steady-state irradiation. Tables 4 and 5 present the synthesis data obtained for the fuel rods using Zy-4 and SS as the cladding material, respectively.

The results show that at higher powers, the fuel centerline temperatures in the fuel rod manufactured using SS are slightly higher than those in the fuel rod manufactured using Zy-4. This is because of higher thermal expansion in SS than in Zy-4. Despite the higher fuel temperatures in SS, the average cladding temperatures in the SS fuel rod are slightly lower than those in the Zy-4 rod because of the higher SS thermal conductivity [18].

The oxide layer thicknesses listed in Tables 4 and 5 for both the considered materials confirm that, under the studied simulation conditions, the oxidation in the Zy-4 fuel rod is much higher than in the SS fuel rod, even considering the properties of $304 \mathrm{SS}$, which is the SS from 300 series more susceptible to undergo oxidation.

The tendencies of evolution for the oxide layer thicknesses as a function of burnup for both the studied materials is shown in Figure 3. Even for the maximum 
Table 5. Data obtained from simulation for SS fuel rod using IPEN-CNEN/SS2.

\begin{tabular}{lrlllll}
\hline & $\begin{array}{l}\text { Time } \\
(\mathrm{h})\end{array}$ & $\begin{array}{l}\text { Burnup } \\
(\mathrm{MW} \mathrm{d} / \mathrm{kg} \mathrm{U})\end{array}$ & $\begin{array}{l}\text { Power } \\
(\mathrm{kW} / \mathrm{m})\end{array}$ & $\begin{array}{l}\text { Average cladding } \\
\text { temperature }\left({ }^{\circ} \mathrm{C}\right)\end{array}$ & $\begin{array}{l}\text { Fuel centerline } \\
\text { temperature }\left({ }^{\circ} \mathrm{C}\right)\end{array}$ & $\begin{array}{l}\text { Oxide layer } \\
\text { thickness }(\mu \mathrm{m})\end{array}$ \\
\hline $\mathbf{1}$ & 235 & 0.24 & 12.17 & 309 & 544 & 0.009 \\
$\mathbf{2}$ & 5035 & 6.80 & 15.91 & 316 & 604 & 0.012 \\
$\mathbf{3}$ & 7373 & 9.94 & 24.70 & 330 & 750 & 0.012 \\
$\mathbf{4}$ & 9353 & 14.05 & 24.18 & 329 & 725 & 0.015 \\
$\mathbf{5}$ & 12629 & 20.71 & 23.62 & 328 & 686 & 0.015 \\
$\mathbf{6}$ & 14069 & 26.38 & 20.51 & 323 & 623 & 0.012 \\
$\mathbf{7}$ & 16711 & 28.02 & 20.47 & 323 & 606 & 0.014 \\
$\mathbf{8}$ & 20237 & 34.09 & 19.95 & 323 & 606 & 0.014 \\
$\mathbf{9}$ & 22404 & 33.39 & 15.42 & 328 & 542 & 0.010 \\
$\mathbf{1 0}$ & 25368 & 37.27 & 15.39 & 328 & 548 & 0.016 \\
$\mathbf{1 1}$ & 28704 & 41.66 & 15.39 & 328 & 555 & 0.016 \\
$\mathbf{1 2}$ & 30480 & 45.94 & 9.74 & 313 & 457 & 0.011 \\
$\mathbf{1 3}$ & 34320 & 49.39 & 11.09 & 317 & 484 & 0.014 \\
$\mathbf{1 4}$ & 37512 & 52.58 & 12.17 & 319 & 508 & 0.014 \\
$\mathbf{1 5}$ & 40080 & 55.37 & 13.19 & 321 & 531 & 0.015 \\
\hline
\end{tabular}

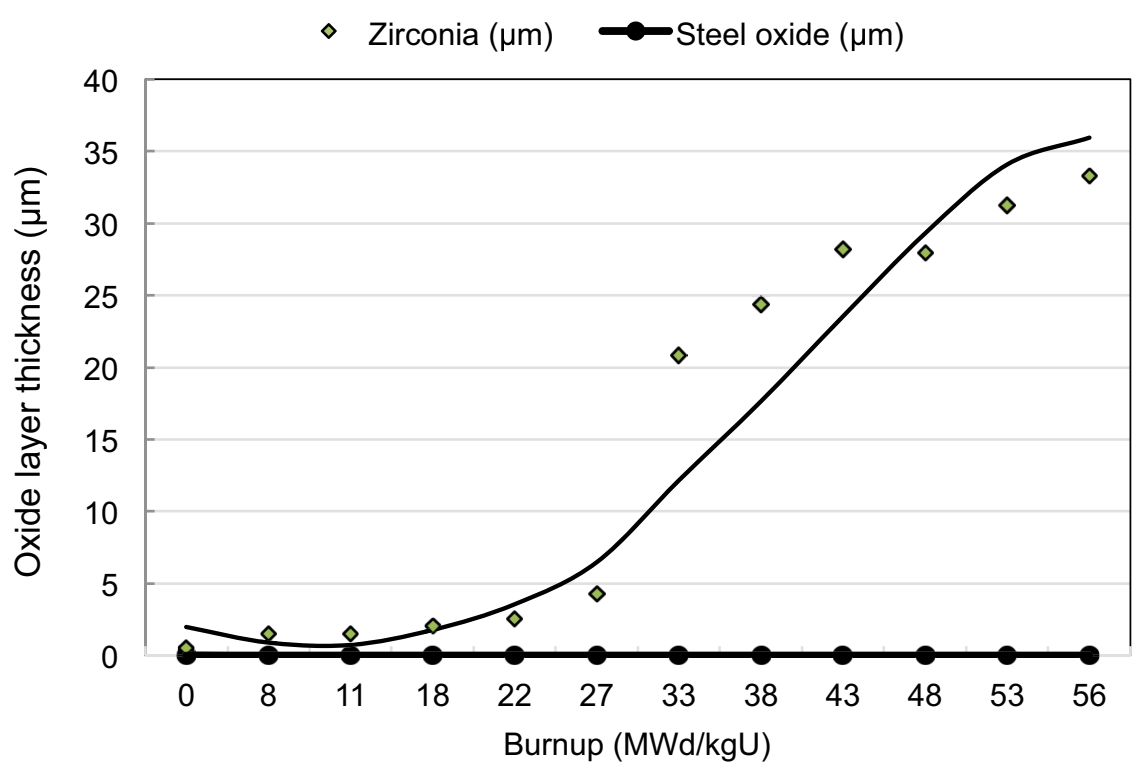

Fig. 3. Oxide layer thickness as a function of burnup for SS and Zy-4 simulated using IPEN-CNEN/SS and FRAPCON codes, respectively.

burnup considered in this study, the oxide layer thickness for the SS fuel rod is lower than that of the Zy-4 fuel rod under steady-state irradiation.

\section{Conclusion}

The results obtained in this study confirmed that for burnup values of up to approximately $55 \mathrm{MW} \mathrm{d} / \mathrm{kg} \mathrm{U}$, SS oxidation under steady-state irradiation in a PWR could be considered negligible, even for $304 \mathrm{SS}$ that is the 300 series SS more susceptible to oxidation. The results obtained show a very low oxide layer thickness comparing to experimental data obtained under PWR conditions [9] but are in agreement with the results observed in the first PWR which operated using SS 304 as cladding material [4]. This study must be extended to evaluate the SS behavior under loss-of-coolant accident and reactivity-initiated accident.

The results of researches developed in different areas of science promoted significant advances to produce high strength and oxidation-resistant steels. Furthermore, the manufacturing and characterization processes used to obtain SS have experienced considerable improvement in the last years. Hence, these advanced steels could be 
treated as alternatives to replace the conventional 300 series steels for use as the cladding material in PWRs. However, it is still necessary to evaluate the mechanical behavior and degradation processes of these advanced materials under irradiation in a PWR environment and to check their performance under design-basis and beyonddesign-basis scenarios.

The authors are grateful for the technical support provided by AMAZUL, USP, and IPEN-CNEN/SP and for the financial support provided by the IAEA to help the authors to attend the TopFuel 2015 meeting.

\section{References}

1. N. Akiyama, H. Sato, K. Naito, Y. Naoi, T. Katsuta, The Fukushima nuclear accident and crisis management-lessons for Japan-U.S. alliance cooperation (Sasakawa Peace Foundation, Tokyo, 2012)

2. K.A. Terrani, S.J. Zinkle, L.L. Snead, Advanced oxidationresistant iron-based alloys for LWR fuel cladding, J. Nucl. Mater. 448, 420 (2014)

3. B.E. Wilde, J.E. Weber, Intergranular stress-corrosion resistance of austenitic stainless steels in water/oxygen environment: accelerated test procedure, Br. Corros. J. 4, 42 (1969)

4. S.M. Stoller Corporation, An evaluation of stainless steel cladding for use in current design LWRs, NP-2642 (EPRI, New York, 1982)

5. A. Abe, C. Giovedi, D.S. Gomes, A. Teixeira e Silva, Revisiting stainless steel as PWR fuel rod cladding after Fukushima Daiichi accident, J. Energy Power Eng. 8, 973 (2014)

6. C.M. Allison et al., SCDAP/RELAP5/MOD3.1 code manual volume IV: MATPRO - a library of materials properties for light-water-reactor accident analysis, NUREG/CR6150.EGG-2720, Washington, 1993
7. G. Was, S.M. Bruemmer, Effects of irradiation on intergranular stress corrosion cracking, J. Nucl. Mater. 216, 326 (1994)

8. K. Arioka, Effect of temperature, hydrogen and boric acid concentration on IGSCC susceptibility of annealed 316 stainless steel, in Contribution of materials investigation to the resolution of problems encountered in pressurized water reactors (Leibniz Information Centre for Science and Technology University Library, Hannover, 2002)

9. T. Terachi et al., Corrosion behavior of stainless steels in simulated PWR primary water - effect of chromium content in alloys and dissolved hydrogen, J. Nucl. Sci. Technol. 45, 975 (2008)

10. P.D. Harvey, Engineering properties of steel (American Society for Metals, Materials Park, OH, 1982)

11. M. Takeda et al., Physical properties of iron-oxide scales on Si-containing steels at high temperature, Mater. Trans. 50, $2242(2009)$

12. H.E. Boyer et al., Handbook, ASM metals (American Society for Metals, Materials Park, OH, 1985)

13. B. Cox et al., Waterside corrosion of zirconium alloys in nuclear power plants, IAEA TECDOC, v. 996 (International Atomic Energy Agency, Vienna, 1998), p. 124

14. P.V. Uffelen et al., Analysis of reactor fuel rod behavior, in Handbook of nuclear engineering (Springer, US, 2010), p. 1519

15. F. Garzarolli, D. Jorde, R. Manzel, J.R. Politano, P.G. Smerd, Waterside corrosion of zircaloy-clad fuel rods in a PWR environment, in Zirconium in the nuclear industry (ASTM International, New York, 1982)

16. R. Vandagriff, Practical guide to industrial boiler systems (CRC Press, New York, 2001)

17. K.J. Geelhood, W.G. Luscher, C.E. Beyer, M.E. Flanagan, FRAPCON-3.4: a computer code for the calculation of steadystate thermal-mechanical behavior of oxide fuel rods for high burnup, NUREG/CR-7022 (U.S. NRC, Washington, 2011)

18. D. Peckner, I.M. Bernstein, Handbook of stainless steels (McGraw-Hill, New York, 1977)

Cite this article as: Daniel de Souza Gomes, Alfredo Abe, Antonio Teixeira e Silva, Claudia Giovedi, Marcelo Ramos Martins, Evaluation of corrosion on the fuel performance of stainless steel cladding, EPJ Nuclear Sci. Technol. 2, 40 (2016) 